\title{
Safeguarding Genetic Resources, Traditional Knowledge, and Traditional Cultural Expressions within the Association of Southeast Asian Nations (ASEAN)
}

\author{
Dina W. Kariodimedjo \\ \{dinawk@gmail.com\} \\ UniversitasGadjahMada, Bulaksumur, Caturtunggal, Kec. Depok, KabupatenSleman, Daerah \\ Istimewa Yogyakarta 55281, Indonesia
}

\begin{abstract}
This article examines efforts to safeguarding genetic resources, traditional knowledge, and regular cultural expressions (GRTKTCE) within the Association of Southeast Asian Nations (ASEAN). It considers ASEAN's legal frameworks and its intellectual property rights action plan on the issue. Also, it discusses challenges in protecting GRTKTCE at the ASEAN level. Mainly, it discusses Indonesia's position, legislation, and policies on the issue. GRTKTCE is one of the characteristics and elements of ASEAN Economic Community Blueprint 2025. It seems that ASEAN is fully committed to working together on this issue. In the broader multilateral level, that is the World Trade Organization and the World Intellectual Property Organization forum, the issue of GRTKTCE has been negotiated for quite a long time. However, the issues still face challenges over its basic concept, including a concept of commercialization and how it could work in practice. This article constitutes initial research findings of the writer's Ph.D. thesis. It covers the legal frameworks, impetus, administration, and implementation of intellectual property rights and GRTKTCE within ASEAN and Indonesia.
\end{abstract}

Keywords: GRTKTCE, ASEAN, Asean Economic Community, Intellectual Property Rights

\section{Introduction}

To support the Association of Southeast Asian Nations (ASEAN) Vision 2020, ASEAN Summit in Bali in 2003 endorsed three pillars, i.e., ASEAN Political-Security Community, ASEAN Economic Community (AEC), and ASEAN Socio-Cultural Community (ASCC) [1]. AEC was effectively in force on 1 January 2016. AEC covers all economic aspects, including free flow of goods, services, investment, capital, skilled labor, intellectual property rights (IPR), business competition, e-commerce, micro, small, and medium enterprises (MSMEs) development, connectivity development, and cooperation on free trade agreements (FTAs) between ASEAN and its dialogue partners.

The issue of Genetic Resources, Traditional Knowledge, and Traditional Cultural Expressions (GRTKTCE) within ASEAN is included in IPR aspect. It is shown in the IPR Action Plan on its Priority Actions from 2008 to 2015. This includes identification of national GRTKTCE and collecting inventory, capacity building, and establishment of a national and regional database. This strategic approach is continued on AEC Blueprint 2025.

This article discusses efforts for safeguarding or protecting GRTKTCE within ASEAN. 
Also, it examines challenges in protecting GRTKTCE at the ASEAN level. Mainly, it discusses Indonesia's position, legislation, and policies on the issue.

\section{GRTKTCE and Intellectual Property Rights}

The exponential development of modernization and globalization towards automation prompts the economic activities in the world to be much more exploitative and consumeristic at the same time. While such progress is beneficial to human civilization, there is a caveat in which the unimpeded access and exploitation of resources and knowledge for commercial use have threatened its natural sustainability to be ceased of existence[2]. Such resources and knowledge are known as Genetic Resources, Traditional Knowledge, and Traditional Cultural Expressions or GRTKTCE. As for which, the World Intellectual Property Organization (WIPO) defines GRTKTCE separately: Genetic resources refer to the genetic material of potential values which encompass any non-human living material whose origin containing functional units of heredity. Traditional knowledge is defined as know-hows that are developed, sustained, and inherited among generations within a community, thus constituting part of its indigenous identity. Lastly, the traditional cultural expressions or "expressions of folklore" are the forms in which traditional culture is expressed and constitutes part of the identity and heritage[3].

There is an awareness of the world community at-large upon the need to foster, preserve, and protect GRTKTC.[4]This resulted in the international recognition uponGRTKTCE within the spectrum of intellectual property rights and law which was established through the promulgation of the Convention on Biological Diversity (CBD) in 1992. This convention formally recognized and obliged the state parties to control the use of their biodiversity (genetic resources, traditional knowledge, and traditional cultural expressions) by protecting, preserving, and beneficially sharing its profits[5].

In the context of intellectual property rights and laws, this convention prompts a debate over GRTKTCE either as cultural property rights through which commercial use is allowed and regulated or as a legal subject of protection and preservation due to its traditional ties to collective identity.[6]Moreover, the issue of GRTKTCE has brought light upon the intersectional issue between the rights of the indigenous community and individual rights of intellectual property [7]. From which the end could lead to either a positive alignment between both. This is due to the nature of CBD, which recognizes and respects intellectual property rights. However, the inclusion of GRTKTCE into the spectrum of intellectual property rights and laws may impose fatal contradictions to the nature of GRTKTCE in which such resources and knowledge does possess not only natural potential values but also social roles which the society shares interchangeably [8].

Moreover, GRTKTCE is the first issue within the intellectual property discussion regarding its inseparable relations to biodiversity, agriculture, medicine, and artistic expressions of indigenous communities, thus confirming its role as part of collective identity[9]. As for collective identity, GRTKTCE also becomes the first issue of debate on "ownership" in which such products and uses of resources and knowledge are construed to which the context of belongingness and origin are contested by particular individuals, ethnic communities, or nation-states[10]. Moreover, even if the GRTKTCE is said to be included within intellectual property legal system of the ASEAN, it is indisputable and irrefutable that such consideration must be aligned with the principles of sustainable development as environmental sustainability, indiscriminate equality, and state recognition and protection upon minorities, which in this case is indigenous community, must be taken 
into account [11].

\section{Methodology}

The research adopts a primarily normative approach relying on ASEAN legal frameworks, its IPR Action Plan, and Indonesia's legal principles and its norms in the form of laws and regulations. Also, it uses an empirical legal approach to understand the attitude of the stateand the related institutions on driving the creation of laws and policy making.

\section{Findings}

The highest structure in ASEAN is ASEAN Summit as a high-level conference whose level consists of the head of States. With regards to economics title, there is ASEAN Economic Minister (AEM) below ASEAN Summit. Indonesia's AEM is its Minister of Trade. Senior Economic Official Meeting (SEOM) works below AEM. Indonesia's SEOM is the Directorate General of International Trade Cooperation, Ministry of Trade. There are several working groups (WG) below SEOM, including WG on IPR. For Indonesia, the vocal point for IPR is in the Directorate General of Intellectual Property (DGIP), Ministry of Law and Human Rights. All working groups, including ASEAN Working Group on Intellectual Property Cooperation (AWGIPC), conduct a regular meeting to discuss issues on each of its sector[12].

The Declaration on the AEC Blueprint 2015, which was signed on 20 November 2007, includes the subtitle of IPR. One of its action plans is to promote regional cooperation on Traditional Knowledge (TK), Genetic Resources (GR), and Cultural Traditional Expressions (CTE). [13]AEC Blueprint 2015 had been concluded on 1 January 2016. Currently, ASEAN is on its way to implementing AEC Blueprint 2025. Within that regard, each working group composes work plan to implement it. In its latest development, all working groups have finalized and agreed key elements or work plan to reach under AEC Blueprint 2025. [13] The-said key elements or work plan is called Strategic Action Plan (SAP), which is only for sectoral working group or sectoral body.

Afterward, working groups will choose the most sensitive, fundamental, and a crucial significant element in ASEAN, which should later be performed by each working group. Key elements which have been chosen by each working group would are then unified, merged, and consolidated into Consolidated SAP (CSAP). CSAP acts as a guideline or reference from working groups. The deal made in AEM retreat in Manilla on early March 2017 has endorsed and authorized CSAP.

Moreover, there is a Committee of the Whole (CoW) who works under SEOM. After a more thorough discussion in any working group, there will always be cross-sectoral issues. Those issues overlap inter sectors or between a working group from one sector with a working group with another sector. For example, the IPR sector, especially GRTKTCE, will overlap with the ASEAN Consultative Committee for Standards and Quality (ACCSQ) on enhancing further development of ASEAN regulatory framework on traditional medicine.

In ASEAN IPR Action Plan 2016-2025, there are four strategic goals of IP in ASEAN. Point 4 of the Strategic Goals is regional mechanisms to promote asset creation and commercialization, particularly geographical indications and TK enhanced [12]. Also, in the Action Plan, there is one initiative, which is Initiative 19: promotes a protection mechanism for GR, TK, and TCE. These facts show political will of ASEAN towards GRTKTCE protection in its region. Meanwhile, there are three priorities of the AWGIPC 
target for 2017 with regards to Strengthening IPRs Cooperation, i.e., accede to the Madrid Protocol, publish the standard guideline on substantive examination of trademarks, and develop a website for MSMEs on IP awareness and training [12].

Although GRTKTCE issue is mentioned as one of the action plans of AEC Blueprint 2015 and 2025, until now there is not any specific agreement on the issue within ASEAN. In the development, there is only the ASEAN Strategic Plan of Action on IP.

The reason for that is not all ASEAN Member States are interested in the GRTKTCErelated matter. One Member State may still need it, but perhaps they are not sure that an intangible cultural heritage (ICH) or GRTKTCE in their country belongs to them. Indonesia may have a similar problem. Even though it is rich in $\mathrm{ICH}$, but one ICH may be coming from other regions, while such TK is developed and widely used within the Indonesian region. The possibility of trouble occurs when Indonesia claims such TK; it turns out that it does not come from Indonesia.

GRTKTCE text within the World Intellectual Property Organization (WIPO) has given basic concept to solve communal claim for the ownership of a GRTKTCE, namely when a GR found or TK claimed or commonly known by two countries. Those two countries must resolve the occurring problems by themselves. As a comparison, the possibility of this conflict may occur in Latin America as they share border and culture. The cross-border movement has existed since long ago. It may also occur within the ASEAN region.

With regards to ASEAN and WIPO, there are 3 to 4 routine meetings called ASEAN Geneva meeting. ASEAN Members' States ambassador attends this meeting to discuss WIPO's implementation at the ASEAN level. When the discussion has reached GRTKTCE related matter, non-proponent Member States tend to block it.

Taking the ASEAN Economic Community (AEC) pillar and ASEAN Socio-Cultural Community (ASCC) pillar into account (ASEAN Secretariat, 2009), IPR, traditional cultural issue, and TK also appear in ASCC pillar. Based on ASCC Blueprint 2025[14], ASCC promotes registration on IPR and strengthens its cooperation and implementation in ASEAN in areas such as food safety, medicines, traditional cultural assets, and biodiversity-based products.

In other words, the issue not only becomes part of economic, but also social and cultural discussion. There are differences of perspective among Member States on GRTKTCE issue. For example, Singapore uses the reason that the issue is a social and cultural issue with declining discussion on GRTKTCE economic value in ASEAN, including benefit sharing and prior informed consent. Since IPR is included in the economic sector, and GRTKTCE is part of the IP, the trade aspects related to the issue shall be discussed in ASEAN. Besides Singapore, the Philippines is also reluctant to engage with the issue since it may still be occupied by internal conflict. GRTKTCE concept will point out segregations among culture-communities in a specific country. It seems that the Philippines has not been ready yet to reach similar GRTKTCE understanding to Indonesia.

Singapore and the Philippines are not part of Like-Minded Countries' (LMC) group in WIPO. ASEAN members other than Singapore and the Philippines are part of LMCs. It is clear, that ASEAN is divided into split positions towards GRTKTCE issue as different priorities, interests, and politic of economies.

The high amount of assembly/meeting within the ASEAN shall be made balanced by requiring diplomats to keep updating and upgrading themselves by studying the related issues. The fact that diplomats are less-sensitive and less-striving in inter-dependent and cross-sector matters should also be taken into consideration. From Indonesia's perspective, the issue can be examined that there is lack of companion from the Ministry of Foreign 
Affairs who is responsible for Indonesia negotiation at international level. Also, the directorates in the Ministry of Foreign Affairs and DGIP as a vocal point for IPR should coordinate more intensively and be integrated to handle such substantial legal issues.

Indonesia has passed legislation and policies on the issue of GRTKTCE, i.e., Copyright Act No. 28 of 2014, which is related with TCE on Articles 38(1), 38(2), 38(4), and 87(1); and Patent Act No. 13 of 2016 on Articles 9 paragraphs d and e, 26(1), and 26(3), which are related with GR, and Articles 9 paragraphs b, d, e, 26(1), 26(3), 49(1), 5(2), 132(1)-point a, 132(2), 132(1)-point b, 132(1)-point d, and 132(4), which are related with TK. Next, there are Trademark and Geographical Indication Act No. 20 of 2016 on Article 1.6, which is related with TK, and Articles 72(2)-point c, 20, 21, 76, and 1.1, which are related with TCE; Industrial Design Act No. 31 of 2000 on its consideration point b which is related with TCE; and Plant Variety Act No. 29 of 2000 on Article 7(1), which is related to GR.

A new Cultural Advancement Act No. 5 of 2017 has responded a need for GRTKTCE protection in Indonesia since GRTKTCE Bill of Act has not been passed yet. Ratifications of Intangible Cultural Heritage (ICH) Convention 2003 by Presidential Regulation No. 78 of 2007, and of Diversity of Cultural Expressions (DCE) Convention 2005 by Presidential Regulation No. 78 of 2011 have been done. Also, policies on the issue were taken by related government ministries. The challenge is that all the laws above should be wellharmonized.

Indonesia's position towards SAP and CSAP[15], which has been endorsed in ASEAN, is expected to be in line with Indonesia's policy. By far, Indonesia's SEOM receives a report on IPR from DGIP, which understands, substantially, the implementation and challenges in the field. Indonesia's SEOM always reminds all vocal points to avoid Indonesia from doing things which are not in line with the conducts endorsed in ASEAN level. SAP shall not be so overwhelming that it could not be implemented. This is to make sure of Indonesia as committing to perform the already-determined SAP. Indonesia's compliance from SAP and ASEAN Blueprint 2015 is shown on ASEAN Score Card, that most of its commitment has been performed; even though some of it is still pending. Based on the performance report, there are several pending homework on turnaround time for registration of trademarks and Hague Agreement.

Indonesia has conducted several activities within the ASEAN framework, namely in the form of sharing experience and inviting WIPO experts. Indonesia's next plan is to create GRTKTCE database at the national level, in cooperation with ASEAN. In the previous time-target, Indonesia became champion country on GRTKTCE, where Indonesia has performed all GRTKTCE programs.

From a perspective of culture, there has not been a systematic action plan performed by the ASEAN Member States in protecting ICH in the scope of ASEAN. Currently, Member States only probe to have a multinational application on case-by-case bases under the UNESCO regime. As a comparison within Asian scope, the cooperation seems more robust. Indonesia's Ministry of Education and Culture tries to detect the potential on the multinational application, e.g., by having cooperation with India. The Ministry has cooperation with Korea, who has the willingness to conduct a seminar on ICH.

When Malaysia claimed tor Torand Gondang Sembilan dances of Indonesia, House of People's Representatives (DewanPerwakilan Rakyat/DPR) summoned the Minister of Education and Culture and its vice minister. DPR wanted to know whether the ICH had been listed in the ministry's inventory. The inventory worked as a basis to show that Indonesia owns an ICH. This is an effective way to counteract or address a claim from other countries. The clash was ended on its own. Malaysia's claim brings a positive impact 
on Indonesia as it raises Indonesia's awareness to protect its $\mathrm{ICH}$, which is relatively low. Indonesia's position on this case, Indonesia will not hamper the access; retrospectively, the other countries shall not claim the culture on its own.

\section{Conclusion}

There arefewer efforts or programs in safeguarding or protecting GRTKTCE within the ASEAN. The report published by ASEAN Secretariat [16] showed limited findings on the the-said issue. There are challenges in protecting the issue within the ASEAN level, i.e., different perspectives on GRTKTCE concept, the priority of interests, and internal challenges by each Member State. Indonesia's position is evident in the issue. Its legislation and policies on GRTKTCE imply that the issue is significant. Future directions for Indonesia are to harmonize and integrate its national laws and coordination among government ministries, and to raise its people's awareness on the said issue.

\section{References}

[1] ASEAN, ASEAN Charter. 2008.

[2] D. A. Spencer, "Fear and hope in an age of mass automation: debating the future of work," New Technol. Work Employ., vol. 33, no. 1, pp. 1-12, 2018.

[3] S. von Lewinski and A. v. (Anja von) Hahn, Indigenous heritage and intellectual property: genetic resources, traditional knowledge and folklore. New York: The Hague and Kluwer Law International, 2004.

[4] C. Antons, "The role of traditional knowledge and access to genetic resources in biodiversity conservation in Southeast Asia," Biodivers. Conserv., vol. 19, no. 4, pp. 1189-1204, Apr. 2010.

[5] C. Lawson and K. Adhikari, "Biodiversity, genetic resources and intellectual property," in Biodiversity, Genetic Resources and Intellectual Property: Developments in Access and Benefit Sharing, 2018.

[6] C. M. Horton, "Protecting Biodiversity and Cultural Diversity under Intellectual Property Law: Toward a New International System,” J. Environ. Law Litig., vol. 1, no. $10,1995$.

[7] L. Helfer, "Toward a Human Rights Framework for Intellectual Property," U.C. Davis Law Rev., 2007.

[8] G. S. Nijar, "Incorporating traditional knowledge in an international regime on access to genetic resources and beneft sharing: Problems and prospects," Eur. J. Int. Law, 2010.

[9] C. Antons, "Asian borderlands and the legal protection of traditional knowledge and traditional cultural expressions," in Modern Asian Studies, 2013.

[10] L. V. Aragon and J. Leach, "Arts and owners: Intellectual property law and the politics of scale in Indonesian arts," Am. Ethnol., 2008.

[11] jo Recht, "Hearing Indigenous Voices, Protecting Indigenous Knowledge," Int. J. Cult. Prop., 2009.

[12] D. (WIPO S. O. Croze, "WIPO's Support of The ASEAN IP Ecosystem,” vol. 6. Singapore, p. 17, 2016.

[13] ASEAN, ASEAN Economic Community Blueprint. 2018.

[14] ASEAN Secretariat, "ASEAN Socio-cultural Community Blueprint," ASEAN Socio-cultural Community Bluepr., 2009. 
[15] AEM and AEC, "ASEAN Economic Community 2025 Consolidated Strategic Action Plan FINAL Endorsed by the AEM and AEC Council on 6 February 2017," 2017.

[16] ASEAN Secretariat, "ASEAN Economic Community 2015: Progress and Key Achievements," 2015. 